\title{
Effect of treatment with the nonsteroidal antiinflammatory meloxicam on milk production, somatic cell count, probability of re-treatment, and culling of dairy cows with mild clinical mastitis
}

\author{
S. McDougall, ${ }^{* 1}$ M. A. Bryan, $\dagger$ and R. M. Tiddy $\ddagger$ \\ *Animal Health Centre, PO Box 21, Morrinsville 3300, New Zealand \\ †Vet South, PO Box 12, Winton 9720, New Zealand \\ ¥Vet Resource, 316 Pokuru Rd., RD 5, Te Awamutu 3800, New Zealand
}

\begin{abstract}
It was hypothesized that treatment of clinical mastitis with a combination of a nonsteroidal antiinflammatory treatment (meloxicam) and a parenteral antibiotic (penethamate hydriodide) would result in lower somatic cell counts (SCC), reduced milk yield losses, improved clinical outcomes, and reduced culling rates compared with antibiotic therapy alone. Cows in 15 herds with clinical mastitis during the first $200 \mathrm{~d}$ of lactation (median $=13 \mathrm{~d}$ ) were treated with $5 \mathrm{~g}$ of penethamate hydriodide daily for $3 \mathrm{~d}$, and one-half these cows were treated with $250 \mathrm{mg}$ of the nonsteroidal antiinflammatory drug meloxicam ( $\mathrm{n}=361$ cows), whereas the other half $(\mathrm{n}=366$ cows) were treated with the vehicle (control group). Milk samples for bacteriology were collected from clinically affected glands before treatment, and samples were collected at $7( \pm 3), 14( \pm 3)$, and $21( \pm 3)$ d after commencement of treatment for SCC determination. Additionally, the rectal temperature, udder edema score, California Mastitis Test score, and milk clot score were determined before treatment and daily milk yield data were collected across the lactation. There were no differences between the treatment groups in calving date, days in milk, age, breed, rectal temperature, California Mastitis Test score, clot score, udder edema score, or bacterial pathogens isolated before treatment. There was no difference between treatment groups in the number of cows that were defined as treatment failures (i.e., re-treated within $24 \mathrm{~d}$ of initial treatment, died, or the treated gland stopped producing milk); 79 (21.9\%) vs. 92 (25.1\%) cows in the meloxicam and control groups failed, respectively. The SCC was lower in the meloxicam-treated group compared with the control group after treatment $[550 \pm 48$ vs. 711 \pm 62 geometric mean $(\times 1,000 / \mathrm{mL}) \pm$ standard error of the mean SCC for quarters after treatment with
\end{abstract}

Received April 8, 2009.

Accepted June 3, 2009.

${ }^{1}$ Corresponding author: smcdoug@ahc.co.nz meloxicam vs. control, respectively]. There was no difference in milk yield for the cows treated with meloxicam compared with the control cows within 28 or $200 \mathrm{~d}$ after treatment. Fewer meloxicam-treated than control cows were removed (culled) from the herds [39/237 $(16.4 \%)$ vs. $67 / 237(28.2 \%)$ for meloxicam vs. control cows, respectively; odds ratio $=0.42,95 \%$ confidence interval $=0.26$ to 0.68$]$. It was concluded that treatment of cows with clinical mastitis with a combination of meloxicam and penethamate resulted in a lower SCC and a reduced risk of removal from the herd (culling) compared with treatment with penethamate alone.

Key words: clinical mastitis, therapy, nonsteroidal antiinflammatory drug

\section{INTRODUCTION}

Mastitis is defined as inflammation of the mammary gland, commonly associated with IMI. Intramammary infection generally triggers an immune response, including an influx of white blood cells, predominantly polymorphonuclear cells (Sordillo et al., 1997; Paape et al., 2003), resulting in an elevated SCC. These cells are attracted into the mammary gland by cytokines, prostaglandins, and complement (Persson et al., 1993; Sordillo et al., 1997). Both gram-positive and gramnegative infections increase the concentrations of IL-1 and tumor necrosis factor- $\alpha$, and gram-negative infections release LPS (Bannerman et al., 2004), which induce production of the enzyme cyclooxygenase (COX; Schmitz et al., 2004). Cyclooxygenase converts arachidonic acid into eicosanoids, including prostaglandins, prostacyclins, and thromboxanes, which act as inflammatory mediators (Smith 2003; Vangroenweghe et al., 2005). Cyclooxygenase has 2 isoforms, designated COX-1 and COX-2. Cyclooxygenase- 1 is constitutively expressed and functions to maintain gastrointestinal mucosal integrity, aid platelet aggregation, and enhance renal blood flow. The COX-2 isoform is inducible and is upregulated in response to inflammatory stimuli. The milk concentrations of the proinflammatory eicosanoids, 
including prostaglandin $\mathrm{E}_{2}, \mathrm{PGF}_{2 \alpha}$, thromboxane $\mathrm{B}_{2}$ (Atroshi et al., 1996), and prostacyclin (Peter et al., 1990), are increased because of IMI.

Given the increases in proinflammatory eicosanoids during mastitis, use of antiinflammatory therapy may be indicated to relieve the local and systemic clinical signs of inflammation and thereby hasten return to normal physiological function of the udder. Nonsteroidal antiinflammatory drugs (NSAID) possess antiinflammatory, antipyretic, and analgesic properties (Smith, 2003). Nonsteroidal antiinflammatory drugs may be nonselective or may selectively inhibit COX-2. It has been shown that the NSAID carprofen, flunixin, and ketoprofen reduce the milk concentrations of thromboxane $\mathrm{B}_{2}$ (Anderson et al., 1986; Banting et al., 2008) and prostaglandin $\mathrm{E}_{2}$ (Vangroenweghe et al., 2005). Only a few field studies have demonstrated that NSAID have beneficial effects in the treatment of field cases of clinical mastitis (Shpigel et al., 1994, 1996). However, the effect of NSAID on milk production and SCC has never been specifically addressed.

Meloxicam is a preferential COX-2 inhibitor (Van Hecken et al., 2000; Lees et al., 2004), which is licensed for use in horses, cattle, pigs, and small animals. It has been demonstrated to reduce milk concentrations of thromboxane $\mathrm{B}_{2}$ during mastitis (Banting et al., 2000), to reduce the plasma concentrations of the $\mathrm{PGF}_{2 \alpha}$ metabolite PGFM in sheep (McKeown et al., 2000) and in endotoxin-challenged cattle (Königsson et al., 2002), and to ameliorate clinical signs of mastitis in dairy cattle (Friton et al., 2002).

Penethamate hydriodide is a $\beta$-lactam antibiotic that has been successfully used for therapy of clinical (McDougall, 1998; Serieys et al., 2005; McDougall et al., 2007) and subclinical (St. Rose et al., 2003; Salat et al., 2008) mastitis. This study aimed to assess the effect of the NSAID meloxicam in conjunction with parenteral antimicrobial therapy (penethamate) on milk production, SCC, clinical outcomes, and culling rate compared with antimicrobial therapy alone.

\section{MATERIALS AND METHODS}

This study was undertaken after approval of the Animal Ethics Committee of AgResearch (Ruakura, Hamilton, New Zealand). The informed consent of all herd owners was obtained before commencement of the study.

Herds $(\mathrm{n}=15)$, comprising a total of 11,163 cows, were enrolled on the basis that they had milking machines and software that recorded the milk production of cows on a daily or milking-by-milking basis and were willing to follow the study protocol. Herds were located in the Waikato $(\mathrm{n}=8)$, Taranaki $(\mathrm{n}=1)$, Canterbury $(\mathrm{n}=4)$, and Southland $(\mathrm{n}=2)$ regions of New Zealand. The average herd size was 744 (range 320 to 3,000 ) cows. Cows calved seasonally, with $84 \%$ of cows in the enrolled herds calving in July and August 2007. Six herds had predominantly Holstein-Friesian cows (i.e., $>75 \%$ of cows in the herds were $>75 \%$ Holstein-Friesian), 1 herd was predominantly Jersey (i.e., $>75 \%$ of cows in the herd were $>75 \%$ Jersey), and the remaining herds had a mixture of Holstein-Friesian, Jersey, and crossbred cows. For all herds, cows were managed on pasture and used supplementary feeds, including hay, corn (Zea mays) silage, pasture silage, palm kernel, and swedes. Milking occurred twice daily.

Cows were enrolled between July 14 and November 11 of 2007 and the cows were between 1 and 200 DIM, with the median being $13 \mathrm{~d}$. Animals eligible for enrollment were lactating dairy cows with producer-defined clinical mastitis [i.e., presence of grossly evident changes to either the milk composition (i.e., clots, blood) or the udder (i.e., swelling or pain)]. Cows were excluded if they were recumbent; had a rectal temperature greater than $41.5^{\circ} \mathrm{C}$; were showing signs of depression, lethargy, diarrhea, or dehydration; or had been treated with either an antibiotic or NSAID in the $7 \mathrm{~d}$ preceding diagnosis of clinical mastitis.

After the diagnosis of clinical mastitis, a technician visited each farm to assess the cow, collect pretreatment samples, and institute treatment. At the time of enrollment (d 0), the producer (or designated staff member) was asked to indicate which glands she or he had diagnosed with clinical mastitis. The technician then scored the degree of udder edema by digital pressure placed on the rear of the udder, on a 1 (no edema) to 5 (grossly edematous) scale (Nestor et al., 1988), and assessed the presence of any clots in the milk, on a 0 (none), 1 (flecks), or 2 (gross clots) scale. The rectal temperature was taken using a digital thermometer. A California Mastitis Test (CMT) was performed on milk from each of the 4 glands for each cow and was scored on a 0 , trace, 1, 2, and 3 scale. For glands diagnosed by producers with clinical mastitis, the teat ends were then scrubbed with a cotton swab moistened in $70 \%$ alcohol. After discarding the first 3 strippings, a milk sample $(>1 \mathrm{~mL})$ was collected into a factory-clean sample vial and labeled. These milk samples were frozen at $-20^{\circ} \mathrm{C}$ before transport to the laboratory, where they were held at $-20^{\circ} \mathrm{C}$ for subsequent bacteriological analysis. At $7( \pm 3), 14( \pm 3)$, and $21( \pm 3)$ d after enrollment, milk samples (minimum of $20 \mathrm{~mL}$ ) were collected from the enrolled gland(s). This occurred at programmed, twice-weekly visits to each herd. The teat end was not aseptically prepared at these times, but the first 3 strippings of milk were discarded before sample collection. These samples were preserved by addition of 1 drop of 
the preservative bronopol and held at $4^{\circ} \mathrm{C}$ for transport and before subsequent SCC analysis.

Each enrolled cow was treated with 3 intramuscular injections of $5 \mathrm{~g}$ of penethamate hydriodide [Mamyzin, Boehringer Ingelheim (NZ) Ltd., Auckland, New Zealand], suspended in $18.5 \mathrm{~mL}$ of sterile water, at approximately 24 -h intervals, commencing at the time of enrollment (d 0).

Additionally, cows were randomized within sequentially presented pairs of animals within each herd to receive, on $\mathrm{d} 0,1)$ a single subcutaneous injection of $250 \mathrm{mg}$ of meloxicam (12.5 mL of Metacam at $20 \mathrm{mg} /$ $\mathrm{mL}$, Boehringer Ingelheim (NZ) Ltd.), or 2) a single subcutaneous injection of $12.5 \mathrm{~mL}$ of the vehicle for meloxicam (control).

To ensure blinding, the vehicle and meloxicam were labeled A and B, respectively, and producers, technicians, and researchers were unaware of the contents. No differential marking of the cows that could allow identification of the treatment group was permitted.

Meat and milk were withheld from supply for 10 and $2 \mathrm{~d}$, respectively, after the last treatment. Milk yield ( $\mathrm{kg} / \mathrm{cow}$ per milking) was recorded using in-line milk yield meters. The data were stored on-farm in propriety software provided by the milking equipment manufacturers. Equipment and software were supplied by Westfalia Landtechnik GmbH (GEA WestfaliaSurge New Zealand Ltd., Cambridge, New Zealand), SAE Afikim (Waikato and Madero Dairy Management, Pukete Industrial Estate, Hamilton, New Zealand), or DeLaval (Te Rapa, Hamilton, New Zealand). Data were available for each milking for the Westfalia and DeLaval software, and as total yield for the day (i.e., the sum of the a.m. and p.m. yields) from the Afikim database.

Cow-level data, including calving date, age, culling date and reason, final milking date of the lactation, and any disease or treatment records, were extracted for each herd from hard-copy records from centrally located electronic recording systems (Mindapro software, LIC, Hamilton, New Zealand) or from the databases associated with the milking equipment at the end of the study. Additionally, at each farm visit, any additional treatment of the cows that were scheduled for resampling was recorded, and the reason(s) for nonpresentation of the cow was recorded. All data was entered into a purpose-built Access database (Microsoft Corporation, Redmond, WA).

\section{Laboratory Procedures}

The frozen d-0 milk samples were thawed at room temperature and inverted 5 times before $10 \mu \mathrm{L}$ of milk was streaked onto a $5 \%$ blood agar plate containing 0.1\% esculin (Fort Richard, Auckland, New Zealand) and incubated at $37^{\circ} \mathrm{C}$ for $48 \mathrm{~h}$. Provisional identification of bacterial genus or species was undertaken on the basis of colony morphology, Gram stain, esculin reaction, tube coagulase, and Christie, Atkins, MunchPetersen tests. Gram-negative rods were subcultured on MacConkey's agar, and oxidase and TSI tests were performed.

An IMI was defined as present when there were $\geq 3$ cfu/plate of each 1 or 2 colony types. A sample was defined as contaminated when $>3$ distinct colony types were present. The SCC samples were held at $4^{\circ} \mathrm{C}$ and submitted within $3 \mathrm{~d}$ of collection for analysis. Analysis was undertaken using fluorooptic methods (Foss 5000, Foss, Hillerød, Denmark).

\section{Statistical Analyses}

The key outcome variables included the $\log _{10}$ individual gland SCC and the cow-level milk yield in the days after diagnosis. Secondary outcomes included clinical treatment failure proportion within $24 \mathrm{~d}$ of enrollment and removal from the herd.

The main explanatory variable was meloxicam treatment (treatment group). However, other potential confounding variables, including age of the cow (coded as 2,3 to 4,5 to $6, \geq 6 \mathrm{yr}$ ), DIM (coded into quartiles, i.e., 1,2 to 4,5 to 14 , and $\geq 15$ DIM), udder edema score (coded as $1,2,3$, and $4+5$ ), milk clot score, rectal temperature (coded into quartiles, i.e., $\leq 38.4,38.5$ to 38.8 , 38.9 to 39.2 , and $\geq 39.3^{\circ} \mathrm{C}$ ), CMT score, front versus rear gland, and bacteria isolated at enrollment [coded as no growth, minor (i.e., CNS, Corynebacterium spp.), or major (i.e., Staphylococcus aureus, Streptococcus uberis, Streptococcus spp., gram-negative rods)], breed of cow (coded as $>11 / 16$ Jersey or Friesian as either Jersey or Friesian, respectively, with the rest coded as crossbreds) were assessed by univariate analyses. Associated variables (i.e., $P<0.2$ ) were included in subsequent multivariable modeling and were left in the final model where significant $(P<0.05)$, where the model goodness of fit was improved, and where inclusion of a variable resulted in a change of $>10 \%$ in the treatment coefficient.

The SCC data were analyzed at the quarter level. The SCC were not normally distributed so were $\log _{10}$ transformed for analysis. Initially, univariate associations between the $\log _{10} \mathrm{SCC}$ and possible predictor variables, including age group, DIM, bacteriological status of the gland, CMT score, edema score, breed of cow, rectal temperature, and sample time (i.e., 7, 14, or $21 \mathrm{~d}$ after treatment), were assessed using ANOVA. Those that were associated $(P<0.2)$ were then used in manual construction of a generalized estimating equation (GEE) to account for the clustering of quarter 
within cow and the repeated-measures nature of the data set (i.e., quarters were sampled at d 7,14 , and 21 after treatment). The corrected quasi-likelihood under independence model criterion (QIC) and the $P$-values were used as the basis for inclusion for the predictor variables. Because there were 19.4 and $22.1 \%$ missing SCC values for the meloxicam and the control group, respectively, the missing values were input using a maximum expectation algorithm assuming a normal distribution of the $\log _{10}$ SCC [missing variable analysis (MVA) procedure in SPSS, version 16.01, SPSS Inc., Chicago, IL]. A mixed model with quarter within cow as the subject effect, sample time as the repeated effect, and herd as a random effect was then created using the same variables as for the GEE model with the data set containing the imputed values. The independent, autoregressive order 1 [AR(1)], and unstructured correlation structures were assessed. The AR(1) covariance structure resulted in the lowest QIC and was used in the final model. The effect of different levels of the predictor variables on SCC were compared using pair-wise comparisons with a Bonferroni adjustment for multiple comparisons. To test the assumption of normality of the residuals, the residuals were plotted as a histogram. Additionally, a scatter plot of the residuals by the predicted values was prepared. No violations of the assumptions were found. The $\log _{10}$ estimated marginal means were back-converted to geometric means and $95 \%$ confidence intervals for presentation.

The milk yield was analyzed at the cow level. The milk production data were screened and individual milk recordings when the yield was $<1$ or $>40 \mathrm{~L}$ were discarded. Additionally, when $>2$ milk production records were present for a cow on $1 \mathrm{~d}$, the data from that day were discarded. Data for the entire lactation for each herd were collated. The interval in days between diagnosis and a specific yield result was calculated. Milk yield for those cows that had calved $>7 \mathrm{~d}$ at the time of diagnosis $(\mathrm{n}=344)$ was described. Milk yield $(\mathrm{kg} / \mathrm{cow}$ per day) was then analyzed using a GEE with volume as the dependent variable and age group, herd, days from diagnosis, week after calving in which mastitis was diagnosed, and treatment group as the predictor variables. The data were analyzed over the first 28 and $200 \mathrm{~d}$ after diagnosis. Independent, $\mathrm{AR}(1)$, and independent correlation structures were assessed. The independent correlation structure was found to have the lowest QIC and was used in subsequent modeling. These data are presented as the estimated marginal means and standard errors of the means. The effect of different levels of the predictor variables on yield were compared using pair-wise comparisons with a Bonferroni adjustment. To test the assumptions of normality

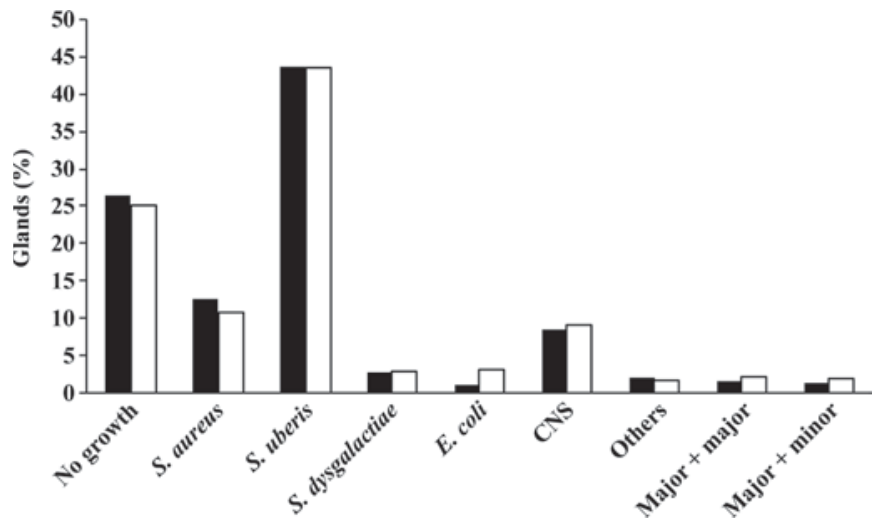

Figure 1. Bacterial species isolated before treatment from glands of cows diagnosed with clinical mastitis and treated with penethamate hydriodide and either meloxicam $(\mathrm{n}=386$ glands; solid bars $)$ or the vehicle (control; $\mathrm{n}=382$ glands; open bars). When 2 bacterial species were isolated from a gland, they were coded as "major + major" (i.e., when 2 major pathogens were isolated and when major pathogens were defined as Staphylococcus aureus, Streptococcus uberis, Streptococcus dysgalactiae, or Escherichia coli) or "major + minor" [i.e., when a major pathogen was isolated with another nonmajor pathogen (e.g., CNS, Corynebacterium spp.)].

of the residuals, the Pearson residuals were plotted as a histogram and as a Q-Q plot. Additionally, a scatter plot of the Pearson residuals by the predicted value was prepared. No violations of the assumptions were found. Attempts to model the yield data using a mixed model failed to converge.

Apparent treatment failure was defined as having occurred when the cow required additional antibiotic treatment for mastitis, when the cow died of mastitis, or when the gland was no longer producing milk within $24 \mathrm{~d}$ of enrollment. The probability of a cow being defined as a treatment failure was initially analyzed at the univariate level, with those predictor variables associated with failure $(P<0.2)$ being offered to a forward and reverse step-wise binary logistic regression model using the likelihood ratio as the inclusion-exclusion criteria. First-order interactions between the variables remaining in the model and the treatment group were tested and removed from the model where $P>0.05$. The hazard of failure was also analyzed using KaplanMeier survival analysis, with the treatment group as the main effect. The equality of survival distributions between the groups was compared using the log rank (Mantel-Cox) test.

The reasons and dates that cows were removed from herds (culled) were obtained from 11 herds, representing 476 of the 727 enrolled cows. However, 1 herd enrolled only 2 cows and neither was removed. This herd was excluded from further analysis because its inclusion resulted in unstable models. Cows were coded as culled (1) or not culled (0), and this variable was used as the 
Table 1. Descriptive data (number of cows) for the categorical variables for cows with mild clinical mastitis randomly assigned to treatment with a single subcutaneous injection of the nonsteroidal antiinflammatory drug meloxicam or the vehicle (control) in addition to 3 treatments of $5 \mathrm{~g}$ of penethamate hydriodide at 24-h intervals $^{1}$

\begin{tabular}{|c|c|c|c|c|c|}
\hline \multirow[b]{2}{*}{ Variable } & \multirow[b]{2}{*}{ Level } & \multicolumn{2}{|c|}{ Group } & \multirow[b]{2}{*}{ Total } & \multirow[b]{2}{*}{$P$-value } \\
\hline & & Meloxicam & Control & & \\
\hline \multirow[t]{4}{*}{ Age (yr) } & 2 & 107 & 127 & 234 & 0.19 \\
\hline & 3 to 4 & 76 & 67 & 143 & \\
\hline & 5 to 6 & 75 & 86 & 161 & \\
\hline & $\geq 6$ & 90 & 73 & 163 & \\
\hline \multirow[t]{3}{*}{ Bacteriology $^{2}$} & $\overline{\text { No growth }}$ & 76 & 79 & 155 & 0.92 \\
\hline & Minor & 33 & 36 & 69 & \\
\hline & Major & 252 & 250 & 502 & \\
\hline \multirow[t]{3}{*}{ Breed $^{3}$} & $\mathrm{~F}$ & 210 & 220 & 430 & 0.42 \\
\hline & XB & 102 & 88 & 190 & \\
\hline & $\mathrm{J}$ & 36 & 42 & 78 & \\
\hline \multirow[t]{4}{*}{ Glands within cow (no.) } & 1 & 293 & 299 & 592 & 0.99 \\
\hline & 2 & 51 & 50 & 101 & \\
\hline & 3 & 10 & 9 & 19 & \\
\hline & 4 & 7 & 7 & 14 & \\
\hline \multirow{3}{*}{ Maximum clot score ${ }^{4}$} & 1 & 90 & 89 & 179 & 0.56 \\
\hline & 2 & 160 & 152 & 312 & \\
\hline & 3 & 106 & 121 & 227 & \\
\hline \multirow[t]{3}{*}{ Maximum CMT score ${ }^{5}$} & 1 & 52 & 40 & 92 & 0.38 \\
\hline & 2 & 143 & 150 & 293 & \\
\hline & 3 & 161 & 169 & 330 & \\
\hline \multirow[t]{4}{*}{ Edema score $^{6}$} & 1 & 117 & 116 & 233 & 0.51 \\
\hline & 2 & 90 & 97 & 187 & \\
\hline & 3 & 72 & 92 & 164 & \\
\hline & $4+5$ & 48 & 43 & 91 & \\
\hline \multirow{4}{*}{ Gland clinical $^{7}$} & $\mathrm{LF}$ & 64 & 66 & 130 & \\
\hline & LR & 158 & 143 & 301 & \\
\hline & $\mathrm{RF}$ & 71 & 76 & 147 & \\
\hline & $\mathrm{RR}$ & 160 & 166 & 326 & \\
\hline
\end{tabular}

${ }^{1}$ The $P$-value is at the univariate level.

${ }^{2}$ Coded as "no growth" if a pathogen was not isolated from any of the enrolled glands, "minor" when only either CNS or Corynebacterium spp. was isolated, and "major" when Staphylococcus aureus, Streptococcus uberis, Streptococcus dysgalactiae, or Escherichia coli was isolated from 1 or more glands.

${ }^{3}$ Categorized as Friesian (F) or Jersey (J) when $\geq 75 \%$ of the cows' genetics were these breeds; otherwise coded as crossbred (XB).

${ }^{4}$ Maximum clot score (on a 1 to 3 scale) of all enrolled glands within the cow.

${ }^{5}$ Maximum California Mastitis Test (CMT) score (on a 0, trace, 1, 2, or 3 scale) of all enrolled glands within the cow.

${ }^{6}$ Cow level edema score (1 to 5 scale, with scores 4 and 5 combined for analysis).

${ }^{7} \mathrm{LF}=$ left front; $\mathrm{LR}=$ left rear; $\mathrm{RF}=$ right front; $\mathrm{RR}=$ right rear.

dependent variable in a binary logistic model similar to the one described above. Additionally, cows were coded as having been removed for not having conceived by the end of the lactation or having conceived, and this was analyzed by chi-square with treatment group as the predictor.

\section{Power Statistics}

The key hypotheses of interest were that the antiinflammatory treatment would result in a higher daily milk yield and a lower $\log _{10} \mathrm{SCC}$ than with penethamate treatment alone. For the milk yield analysis, it was assumed that meloxicam might reduce milk losses by $25 \%$ compared with control cows, resulting in a difference of $0.6 \mathrm{~kg} / \mathrm{d}$ over a period of $200 \mathrm{~d}$ (Friton and Banting, 2005). To detect such a difference, given a standard deviation of milk production of $3 \mathrm{~kg} / \mathrm{cow}$ per day, approximately 400 cows/treatment group $(\alpha=0.05$; $\beta=0.2$ ) were needed. For the $\log _{10}$ SCC, 134 cows/ treatment group were required $(\alpha=0.05 ; \beta=0.2)$, assuming a standard deviation of 0.5 and the desire to detect a $0.2-\log$ difference in $\log _{10}$ SCC.

\section{RESULTS}

A total of 727 cows were enrolled in the study. Of these, 361 cows (453 quarters) and 366 cows (451 quar- 


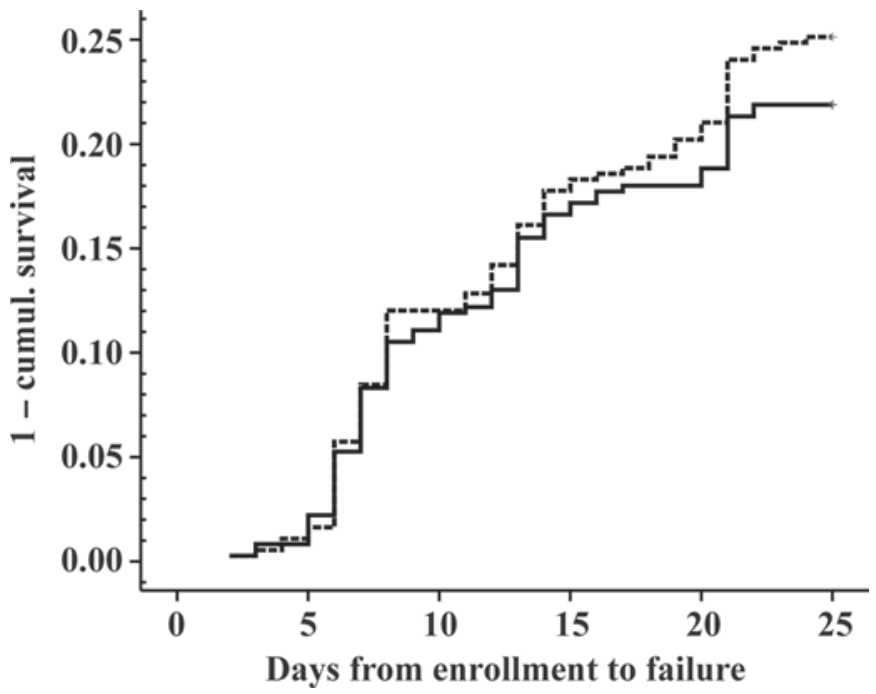

Figure 2. Kaplan-Meier survival curve for the interval between enrollment and clinical treatment failure (days) for cows with clinical mastitis treated with penethamate hydriodide and either meloxicam (solid line) or the vehicle (control; broken line).

ters) were allocated to the meloxicam and the control group, respectively.

There were no differences between the groups in age, breed, distribution of bacterial species isolated at the time of enrollment $(P=0.67$; Figure 1$)$, number of affected glands within a cow, maximum CMT score within a cow, maximum clot score with a cow, edema score, or distribution of glands within the udder (Table 1). The groups also did not differ in terms of calving date [August $9 \pm 19$ vs. August $8 \pm 23$ (mean \pm SD) for meloxicam vs. control], DIM ( $12 \pm 18$ vs. $15 \pm 29$ for meloxicam vs. control), or rectal temperature (38.8 \pm 0.7 vs. $38.8 \pm 0.7^{\circ} \mathrm{C}$ for meloxicam vs. control) at the time of enrollment (all $P>0.15$ ).

\section{Clinical Treatment Failure After Treatment}

An apparent clinical treatment failure within $24 \mathrm{~d}$ of enrollment was observed in $79(21.9 \%)$ and $92(25.1 \%)$ cows in the meloxicam group and the control group, respectively $(P=0.35$; Table 2$)$. Failure reasons included death (2 in the meloxicam group, 0 in the control group), the gland no longer producing milk (6 in the meloxicam group, 2 in the control group), and removal from the herd ( 0 in the meloxicam group, 3 in the control group), with the remaining failures attributable to re-treatment.

Treatment failure varied among herds, was lower when diagnosis occurred 3 to $5 \mathrm{~d}$ after calving than at other times, was higher in cows with an edema score of 4 or 5 relative to a score of 1 , was higher for cows with a maximum CMT score of 2 or 3 relative to a score of $<2$, and was more likely in rear glands than in fore glands. There were no significant interactions between treat-

Table 2. Odds ratio (OR) and 95\% confidence intervals (95\% CI) of the odds ratio for cows being defined as clinical treatment failures after treatment for clinical mastitis with a single subcutaneous injection of the nonsteroidal antiinflammatory drug meloxicam or the vehicle (control) in addition to 3 treatments of $5 \mathrm{~g}$ of penethamate hydriodide at 24 -h intervals

\begin{tabular}{|c|c|c|c|c|c|c|c|c|}
\hline \multirow[b]{2}{*}{ Variable } & \multirow[b]{2}{*}{ Coefficient } & \multirow[b]{2}{*}{ SE } & \multirow[b]{2}{*}{ Wald } & \multirow[b]{2}{*}{ df } & \multirow[b]{2}{*}{$P$-value } & \multirow[b]{2}{*}{ OR } & \multicolumn{2}{|c|}{$95 \%$ CI } \\
\hline & & & & & & & Low & High \\
\hline Herd & & & 54.48 & 14 & 0.00 & & & \\
\hline $\mathrm{DIM}^{1}$ & & & 7.15 & 3 & 0.07 & & & \\
\hline 3 to 5 & -0.87 & 0.36 & 5.94 & 1 & 0.01 & 0.42 & 0.21 & 0.84 \\
\hline 6 to 17 & -0.12 & 0.32 & 0.15 & 1 & 0.70 & 0.89 & 0.48 & 1.64 \\
\hline$\geq 18$ & 0.02 & 0.29 & 0.00 & 1 & 0.95 & 1.02 & 0.57 & 1.82 \\
\hline Treatment $^{2}$ & 0.20 & 0.21 & 0.88 & 1 & 0.35 & 1.22 & 0.80 & 1.86 \\
\hline Edema score $^{3}$ & & & 14.24 & 3 & 0.00 & & & \\
\hline 2 & -0.16 & 0.32 & 0.24 & 1 & 0.63 & 0.86 & 0.46 & 1.60 \\
\hline 3 & -0.20 & 0.32 & 0.38 & 1 & 0.54 & 0.82 & 0.43 & 1.55 \\
\hline $4+5$ & 0.96 & 0.35 & 7.28 & 1 & 0.01 & 2.60 & 1.30 & 5.20 \\
\hline CMT score ${ }^{4}$ & & & 6.96 & 2 & 0.03 & & & \\
\hline 2 & 0.81 & 0.46 & 3.20 & 1 & 0.07 & 2.26 & 0.92 & 5.52 \\
\hline 3 & 1.20 & 0.48 & 6.36 & 1 & 0.01 & 3.31 & 1.31 & 8.41 \\
\hline Gland position ${ }^{5}$ & 0.75 & 0.29 & 6.98 & 1 & 0.01 & 2.13 & 1.22 & 3.72 \\
\hline Constant & -4.13 & 0.78 & 27.80 & 1 & 0.00 & 0.02 & & \\
\hline
\end{tabular}

${ }^{1}$ Enrollment at $<3 \mathrm{~d}$ after calving is the reference category.

${ }^{2}$ The control group is the reference category.

${ }^{3}$ Maximum edema score of 1 is the reference category.

${ }^{4}$ The maximum California Mastitis Test (CMT) score of all glands enrolled, with a cow scoring 1 as the reference category.

${ }^{5}$ Cows with only a front gland affected is the reference category. 


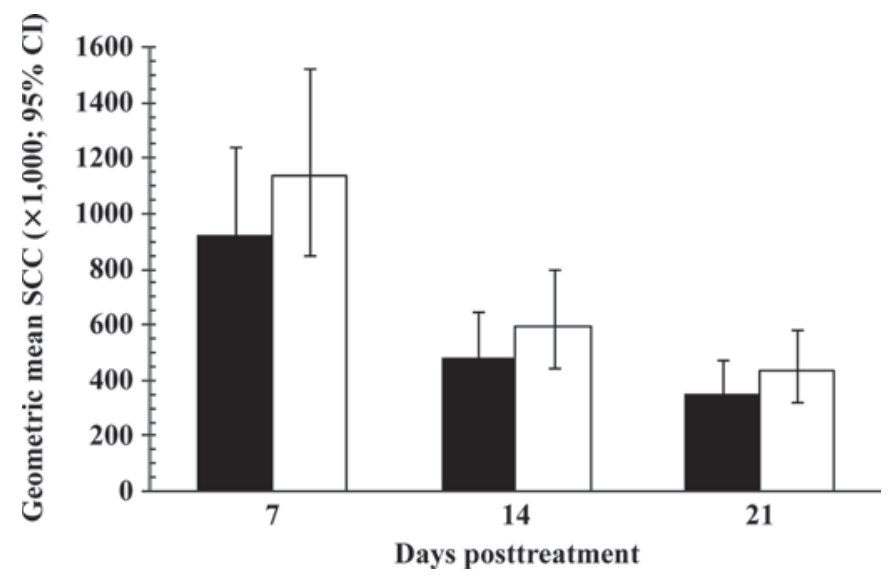

Figure 3. The geometric mean (95\% confidence intervals) SCC/ $\mathrm{mL}(\times 1,000)$ for glands of cows with clinical mastitis treated with penethamate hydriodide and either meloxicam (solid bars) or the vehicle (control; open bars) 7, 14, and $21 \mathrm{~d}$ after treatment.

ment and any of the other variables in the final model (all $P>0.4$; Table 2). The timing of clinical treatment failure did not differ between treatment groups in the Kaplan-Meier analysis $(P=0.33$; Figure 2$)$.

\section{SCC}

The overall SCC was lower in the meloxicam-treated group than in the control group $[550 \pm 48$ vs. $711 \pm$ 62 geometric mean $(\times 1,000 / \mathrm{mL}) \pm \mathrm{SE} \mathrm{SCC} / \mathrm{mL}$ for quarters after treatment with meloxicam or the vehicle, respectively; $P=0.001]$. The SCC declined with time after treatment (Table 3; $P<0.01$ ), was lower in 2 -yrold cows than older cows (Table $3 ; P<0.01$ ), increased with days after calving at diagnosis (Table $3 ; P<0.01$ ), and was lower in cows from which no pathogen was isolated compared with cows with either minor or major bacterial pathogens isolated (Table $3 ; P<0.01$ ). There was no interaction between treatment and days after treatment (Figure 3; $P=0.67$ ) and no interaction between treatment group and any of the other variables in the final model $(P>0.2)$. The inferences and estimates of effect were similar for the models using the initial data and the models using the data set for which values were imputed.

\section{Milk Production Analysis}

Milk yield declined by approximately $8 \mathrm{~kg}$ over the $7 \mathrm{~d}$ preceding diagnosis of mastitis (Figure 4a). There was no difference in milk yield for cows in the meloxicam or the control group within $28 \mathrm{~d}[22.6 \pm 0.5$ and. $22.8 \pm 0.5$ (mean $\pm \mathrm{SEM}$ ) kg/cow per day, respectively, $P=0.69$; Figure 4b] or $200 \mathrm{~d}[18.7 \pm 0.4$ and $19.0 \pm$ 0.4 (mean $\pm \mathrm{SEM}$ ) $\mathrm{kg} /$ cow per day, respectively, $P=$ 0.28 ] of diagnosis. The milk yield was affected by age of the cow, the edema score, week after calving in which the diagnosis of clinical mastitis occurred, and breed of cow (Table 4).

\section{Removal (Culling)}

Fewer cows from the meloxicam than the control group were removed from the herds [39/237 (16.4\%) vs. $67 / 237(28.2 \%)$, respectively; odds ratio $=0.42,95 \%$ confidence interval $=0.26$ to $0.68 ; P<0.001$; Table 5 and Figure 5). Only 1 and 3 cows were removed from

Table 3. Geometric mean SCC $(\times 1,000 \mathrm{SCC} / \mathrm{mL})$ and $95 \%$ confidence intervals $(95 \% \mathrm{CI})$ for glands of cows with clinical mastitis randomly assigned to treatment with a single subcutaneous injection of the nonsteroidal antiinflammatory drug meloxicam or the vehicle (control) in addition to 3 treatments of $5 \mathrm{~g}$ of penethamate hydriodide at 24 -h intervals

\begin{tabular}{|c|c|c|c|c|}
\hline \multirow[b]{2}{*}{ Variable } & \multirow[b]{2}{*}{ Level } & \multirow[b]{2}{*}{ Geometric mean } & \multicolumn{2}{|c|}{$95 \% \mathrm{CI}$} \\
\hline & & & Low & High \\
\hline \multirow[t]{4}{*}{ Age (yr) } & 2 & $397^{\mathrm{a}}$ & 295 & 533 \\
\hline & 3 to 4 & $554^{\mathrm{ab}}$ & 400 & 769 \\
\hline & 5 to 6 & $700^{\mathrm{bc}}$ & 508 & 963 \\
\hline & $7+$ & $844^{\mathrm{c}}$ & 615 & 1,157 \\
\hline \multirow[t]{3}{*}{ Days postdiagnosis } & 7 & $1,026^{\mathrm{a}}$ & 776 & 1,358 \\
\hline & 14 & $538^{\mathrm{b}}$ & 406 & 713 \\
\hline & 21 & $392^{\mathrm{c}}$ & 295 & 520 \\
\hline \multirow{4}{*}{ DIM at diagnosis } & $\leq 1$ & $528^{\mathrm{a}}$ & 390 & 717 \\
\hline & $\overline{2}$ to 4 & $519^{\mathrm{a}}$ & 381 & 707 \\
\hline & 5 to 13 & $606^{\mathrm{ab}}$ & 436 & 843 \\
\hline & $14+$ & $781^{\mathrm{b}}$ & 571 & 1,069 \\
\hline \multirow[t]{3}{*}{ Bacteria isolated } & No growth & $346^{\mathrm{a}}$ & 255 & 468 \\
\hline & Minor pathogen & $576^{\mathrm{b}}$ & 399 & 831 \\
\hline & Major pathogen & $1,085^{\mathrm{c}}$ & 828 & 1,422 \\
\hline
\end{tabular}

${ }^{\mathrm{a}-\mathrm{c}}$ Within a variable, means with different superscripts differ at $P<0.05$. 

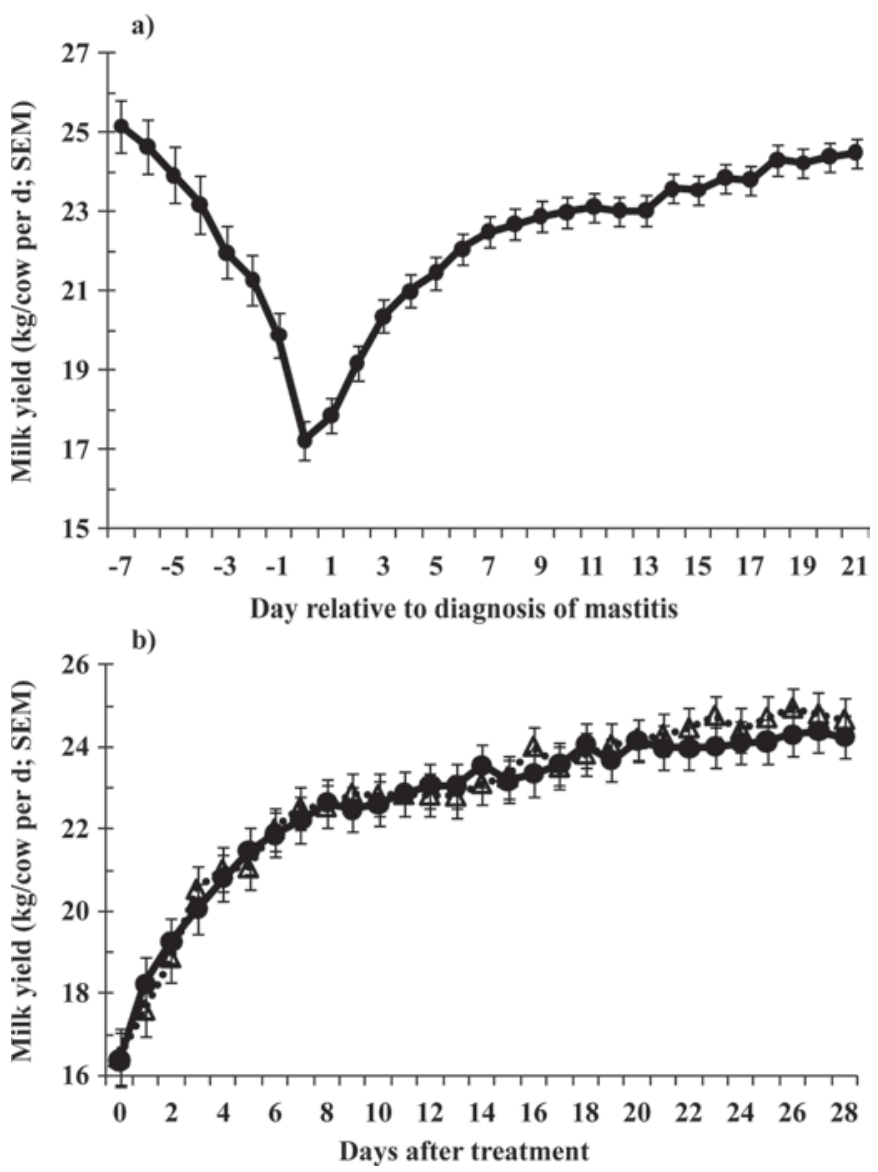

Figure 4. Estimated marginal means (SEM) for average daily milk yield $(\mathrm{kg} / \mathrm{cow}$ per day) of a) all cows calved at least $7 \mathrm{~d}$ at the time of diagnosis of clinical mastitis, for the $7 \mathrm{~d}$ before and $21 \mathrm{~d}$ after diagnosis, and b) for cows in the $28 \mathrm{~d}$ after diagnosis of clinical mastitis that were randomly treated with penethamate hydriodide and either meloxicam $(\bullet)$ or the vehicle (control; $\Delta$ ).

the meloxicam and the control group, respectively, for mastitis-related reasons. Fewer meloxicam than control cows were removed for failing to conceive $[8 / 237(3.4 \%)$ vs. $20 / 237(8.4 \%)$, respectively; odds ratio $=0.37,95 \%$ confidence interval $=0.16$ to $0.86 ; P=0.02]$. Removal increased with age $(P<0.001$; Table 5$)$ and varied among herds $(P=0.003)$. There was no interaction of treatment with age or herd (both $P>0.2$ ). Days in milk, CMT score, clot score, rectal temperature, breed, and bacterial status were not associated with risk of removal (all $P>0.2$ ) at the univariate level.

\section{DISCUSSION}

Addition of an NSAID (meloxicam) to antibiotic therapy of clinical mastitis cases resulted in a lower SCC and a reduced risk of removal (culling). Meloxicam treatment did not alter the risk of clinical treatment failure (i.e., re-treatment, death, or loss of gland function within $24 \mathrm{~d}$ of enrollment) or the increase in milk yield over 28 or $200 \mathrm{~d}$ after treatment.

The clinical mastitis cases enrolled in the current study were mild cases; that is, there were grossly apparent changes in the milk with or without local inflammation in the mammary gland (Erskine et al., 2003). By design, severe cases, that is, those involving systemic changes, were excluded. Severe cases are often seen by veterinarians, who will often use NSAID in conjunction with antimicrobial therapy. The current study was specifically designed to assess the effects of NSIAD use in mild cases of clinical mastitis, which are the most common form under New Zealand conditions. Many of the previous studies on the effects of NSAID therapy in mastitis have used LPS-induced mastitis (Anderson and Hunt 1989) or experimental Escherichia coli infections (Vangroenweghe et al., 2005). Although such studies are valuable because they allow detailed examination and sampling of cows, the outcomes may not reflect those found in naturally occurring mild cases of clinical mastitis.

Table 4. Estimated marginal means, standard errors of the means, and $95 \%$ confidence intervals (95\% CI) for average daily milk yield $(\mathrm{kg} / \mathrm{cow}$ per day) in the $28 \mathrm{~d}$ after diagnosis and treatment for cows with clinical mastitis randomly assigned to treatment with a single subcutaneous injection of the nonsteroidal antiinflammatory drug meloxicam or the vehicle (control) in addition to 3 treatments of $5 \mathrm{~g}$ of penethamate hydriodide at 24 -h intervals

\begin{tabular}{llllll}
\hline & & & & \multicolumn{2}{c}{$95 \%$ CI } \\
\cline { 5 - 6 } Variable & & & & \\
\cline { 4 - 6 } & Level & Mean & SEM & Low & High \\
\hline Age (yr) & 2 & $17.9^{\mathrm{a}}$ & 0.6 & 16.8 & 19.0 \\
& 3 to 4 & $23.5^{\mathrm{b}}$ & 0.6 & 22.3 & 24.6 \\
& 5 to 6 & $24 .^{\text {bc }}$ & 0.5 & 23.0 & 25.1 \\
Edema code & $7+$ & $25.3^{\mathrm{c}}$ & 0.6 & 24.2 & 26.5 \\
& 1 & $21.6^{\mathrm{a}}$ & 0.5 & 20.6 & 22.5 \\
& 2 & $22.6^{\text {ab }}$ & 0.6 & 21.5 & 23.8 \\
Week in milk & 3 & $22.7^{\text {ab }}$ & 0.6 & 21.5 & 23.9 \\
& $4+5$ & $23.8^{\mathrm{b}}$ & 0.6 & 22.6 & 25.1 \\
& 1 & 23.1 & 0.4 & 22.4 & 23.8 \\
& 2 & 23.1 & 0.7 & 21.7 & 24.5 \\
& 3 & 25.0 & 0.7 & 23.6 & 26.3 \\
& 4 & 25.2 & 1.1 & 23.1 & 27.4 \\
& 5 & 25.0 & 1.0 & 23.1 & 26.9 \\
& 6 & 24.3 & 0.8 & 22.8 & 25.9 \\
& 7 & 26.5 & 1.1 & 24.4 & 28.7 \\
& 8 & 18.6 & 1.1 & 16.4 & 20.8 \\
& 9 & 21.0 & 1.4 & 18.2 & 23.7 \\
& 10 & 21.8 & 2.4 & 17.2 & 26.5 \\
& 11 & 17.2 & 2.2 & 12.9 & 21.4 \\
& 12 & 22.3 & 1.3 & 19.8 & 24.8 \\
& 14 & 23.3 & 1.1 & 21.2 & 25.5 \\
& 19 & 21.2 & 0.9 & 19.5 & 22.9 \\
& Friesian & $23.9^{\mathrm{a}}$ & 0.5 & 22.9 & 24.9 \\
& Crossbreed & $23.2^{\text {ab }}$ & 0.6 & 22.1 & 24.3 \\
& Jersey & $21.0^{\mathrm{b}}$ & 0.7 & 19.6 & 22.3 \\
\hline
\end{tabular}

${ }^{\mathrm{a}-\mathrm{c}}$ Means within a variable with different superscripts differ at $P<$ 0.05 . 
Table 5. Odds ratio (OR) and 95\% confidence intervals (95\% CI) for removal (culling) of cows diagnosed with clinical mastitis randomly assigned to treatment with a single subcutaneous injection of the nonsteroidal antiinflammatory drug meloxicam or the vehicle (control) in addition to 3 treatments of $5 \mathrm{~g}$ of penethamate hydriodide at 24 -h intervals ${ }^{1}$

\begin{tabular}{|c|c|c|c|c|c|c|c|}
\hline \multirow[b]{2}{*}{ Variable } & \multirow[b]{2}{*}{ Level } & \multirow[b]{2}{*}{ Wald chi-square } & \multirow[b]{2}{*}{ df } & \multirow[b]{2}{*}{$P$-value } & \multirow[b]{2}{*}{ OR } & \multicolumn{2}{|c|}{$95 \% \mathrm{CI}$} \\
\hline & & & & & & Low & High \\
\hline Intercept & & 5.968 & 1 & 0.015 & 0.28 & 0.10 & 0.78 \\
\hline \multirow{4}{*}{$\operatorname{Age}^{2}(\mathrm{yr})$} & 2 & 20.151 & 1 & 0.000 & 0.24 & 0.13 & 0.44 \\
\hline & 3 to 4 & 9.899 & 1 & 0.002 & 0.30 & 0.14 & 0.63 \\
\hline & 5 to 6 & 5.155 & 1 & 0.023 & 0.47 & 0.24 & 0.90 \\
\hline & $\geq 7$ & - & - & - & 1.00 & - & - \\
\hline \multirow{2}{*}{ Treatment $^{3}$} & Meloxicam & 12.646 & 1 & 0.000 & 0.42 & 0.26 & 0.68 \\
\hline & Control & - & - & - & 1.00 & - & - \\
\hline
\end{tabular}

${ }^{1}$ Herd was significant in the model, but the data are not presented for clarity.

${ }^{2}$ Reference category is $\geq 7$-yr-old cows.

${ }^{3}$ Reference category is the control group.

The study design was blinded, with the producers, technicians, laboratory staff, and investigators unaware of the identity of the treatments until after data analysis. Thus, the risk of allocation, treatment, or posttreatment bias appears low. The treatment groups were balanced for age, breed, and calving date and were balanced within herd, indicating that no allocation bias occurred.

Approximately $25 \%$ of the enrolled cows were either re-treated, died, or defined as having lost functionality in one of more glands within $24 \mathrm{~d}$ after treatment. The rate of clinical treatment failure was similar between groups, and is similar to that reported in other clinical mastitis intervention studies in New Zealand (McDougall et al., 2007). Producers did not have access to the microbiology or SCC data; hence, the decision to re-treat a cow was based on clinical criteria such as the gross milk composition and gland appearance. Not unexpectedly, higher edema and CMT scores at enrollment were associated with a higher risk of clinical treatment failure. Presumably, cows with more clinically severe mastitis at enrollment were more likely to have ongoing grossly evident changes to milk or the gland than those that initially had less severe clinical signs. There was no interaction between the edema or CMT score and treatment group on the risk of clinical failure. This indicates that the effect of the NSAID treatment was the same in cows with a range of severity of clinical signs. It might have been expected that NSAID treatment might reduce the clinical severity of signs and hence reduce the probability of apparent clinical failure. In an Israeli field study, NSAID therapy resulted in a higher clinical recovery rate than when NSAID were not used (Shpigel et al., 1994), and use of meloxicam reduced the clinical score compared with no treatment in preliminary results from a European study (Friton et al., 2002).
The current study demonstrated that treatment with meloxicam resulted in a lower SCC after treatment. There was no treatment $\times$ time after treatment interaction for SCC, indicating that the SCC was consistently lower across time in the meloxicam group. This appears to be a novel finding because SCC was not altered by treatment with carprofen, compared with a saline control, in E. coli-challenged cows (Vangroenweghe et al., 2005) or after treatment of LPS-induced mastitis with flunixin (Anderson and Hunt, 1989).

Milk yield was depressed before and after the diagnosis of clinical mastitis. It is beyond the scope of this study to describe the magnitude of the losses associated with clinical mastitis; rather, the intention was to evaluate whether the use of meloxicam would ameliorate this loss. These data are in agreement with previous studies illustrating depression of milk yield associated with clinical mastitis (Gröhn et al. 2004). As in previ-

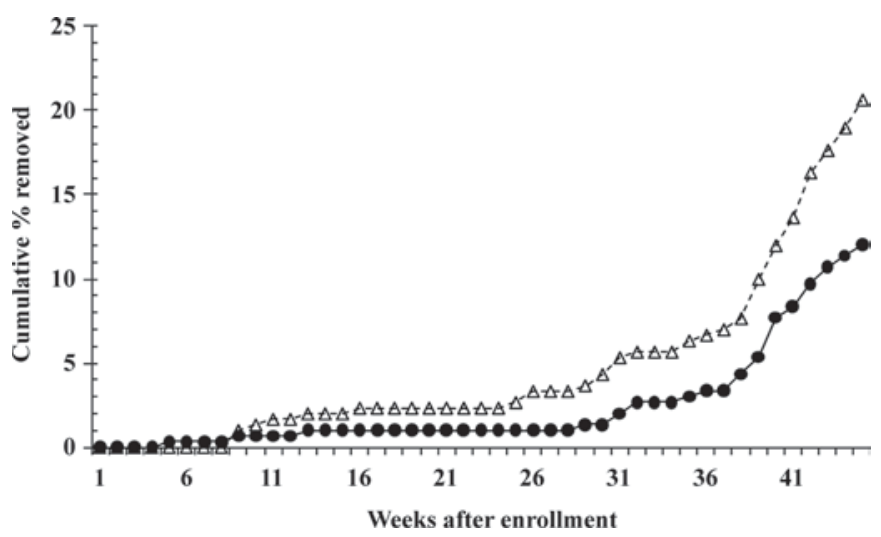

Figure 5. Cumulative percentage of cows with clinical mastitis treated with penethamate hydriodide and either meloxicam $(\bullet)$ or the vehicle (control; $\Delta$ ) that were removed (culled) during the 45 wk after enrollment. 
ous, smaller studies of NSAID treatment of mastitis (Anderson et al., 1986; Wagner and Apley, 2004; Vangroenweghe et al., 2005), no difference in milk yield was detected between the NSAID (meloxicam) and control groups in the current study. This inference held when analysis occurred over 28 or 200 d after treatment. The current study had sufficient cases to detect a difference of approximately $1.5 \mathrm{~kg} / \mathrm{cow}$ per day in milk yield (PASS 2008, NCSS, Kaysville, UT) when using 360 cases/treatment group and a standard deviation in daily milk yield of approximately $7 \mathrm{~kg}$, as was found in the current study. Hence, it can be inferred that if there was any reduction in milk yield depression from using NSAID, it was less than $1.5 \mathrm{~kg} /$ cow per day.

Meloxicam treatment was associated with a reduction in the risk of removal from the herd. Mastitis or mastitis-related reasons were listed as the reason for removal by producers in only a small number of cases ( 1 in the meloxicam group, 3 in the control group). Nearly one-half the removals were listed as "surplus to requirements." Producers usually choose to remove poorer performing cows. Thus, it is likely that some cows culled for mastitis-associated reasons may be included in this surplus to requirements category. Cows treated with meloxicam were less likely to be removed from the herds for having failed to conceive. It has been demonstrated that cows that were diagnosed with clinical mastitis were at higher risk of removal from the herd (for all reasons) than cows that were not diagnosed with clinical mastitis (Santos et al., 2004). It has also been demonstrated that mastitis results in a longer interval from calving to conception, more services per conception (Barker et al., 1998), lower conception rates (Santos et al., 2004), and a higher risk of embryo loss (Chebel et al., 2004; McDougall et al., 2005). One mechanism for these effects is that IMI results in elevated concentrations of $\mathrm{PGF}_{2 \alpha}$, which may result in luteolysis and early embryonic loss. Experimental IMI resulted in higher concentrations of PGFM (a metabolite of $\mathrm{PGF}_{2 \alpha}$ ) after oxytocin challenge than in control cows (Hockett et al., 2000). Another mechanism may be interruption of normal estrous cycles because cows with experimental IMI were less likely to undergo induced luteolysis and had longer intervals to estrus (Hockett et al., 2005). Thus, a direct effect of meloxicam in reducing the risk of abnormal cyclicity before conception or luteolysis in early pregnancy is possible. However, the majority of cases in the current study occurred in early lactation, before the seasonal breeding had commenced. Hence, the effects of treatment may be indirect, potentially through more rapid return to normal rumen function (Banting et al. 2008), reduced severity of cases of chronic mastitis, interruptions to resumption of normal postpartum estrous cycles, or a combination of these factors.
In conclusion, treatment of clinical mastitis cases with the NSAID meloxicam, in combination with the parenteral antibiotic penethamate resulted in a lower SCC and a lower likelihood of culling than for the control cows. Meloxicam treatment did not alter the risk of clinical treatment failure or reduce milk losses caused by mastitis over 28 or $200 \mathrm{~d}$ after treatment.

\section{ACKNOWLEDGMENTS}

The commitment of the producers and their staff and the field and laboratory technicians in completing this study is gratefully acknowledged. Harold Henderson (AgResearch, Ruakura, Hamilton, New Zealand) provided invaluable statistical advice. Funding for this study was provided by Boehringer Ingelheim (NZ) Ltd. (Auckland, New Zealand) and Boehringer Ingelheim Vetmedica GmbH (Ingelheim, Germany).

\section{REFERENCES}

Anderson, K. L., and E. Hunt. 1989. Anti-inflammatory therapy in acute endotoxin-induced bovine mastitis. Vet. Res. Commun. 13:17-26.

Anderson, K. L., A. R. Smith, R. D. Shanks, L. E. Davis, and B. K. Gustafsson. 1986. Efficacy of flunixin meglumine for the treatment of endotoxin-induced bovine mastitis. Am. J. Vet. Res. 47:13661372

Atroshi, F., J. Parantainen, S. Sankari, M. Jarvinen, L. A. Lindberg, and H. Saloniemi. 1996. Changes in inflammation-related blood constituents of mastitic cows. Vet. Res. 27:125-132.

Bannerman, D. D., M. J. Paape, J. P. Goff, K. Kimura, J. D. Lippolis, and J. C. Hope. 2004. Innate immune responses to intramammary infection with Serratia marcescens and Streptococcus uberis. Vet. Res. 35:681-700.

Banting, A., S. Banting, K. Heinonen, and K. Mustonen. 2008. Efficacy of oral and parenteral ketoprofen in lactating cows with endotoxininduced acute mastitis. Vet. Rec. 63:506-509.

Banting, A., H. Schmidt, and S. Banting. 2000. Efficacy of meloxicam in lactating cows with $E$. coli endotoxin induced acute mastitis. J. Vet. Pharmacol. Ther. 23(Suppl. 1.):E4. (Abstr.)

Barker, A. R., F. N. Schrick, M. J. Lewis, H. H. Dowlen, and S. P. Oliver. 1998. Influence of clinical mastitis during early lactation on reproductive-performance of Jersey cows. J. Dairy Sci. 81:12851290.

Chebel, R. C., J. E. P. Santos, J. P. Reynolds, R. L. A. Cerri, S. G. Juchem, and M. Overton. 2004. Factors affecting conception rate after artificial insemination and pregnancy loss in lactating dairy cows. Anim. Reprod. Sci. 84:239-255.

Erskine, R. J., S. Wagner, and F. J. DeGraves. 2003. Mastitis therapy and pharmacology. Vet. Clin. North Am. Food Anim. Pract. 19:109-138.

Friton, G., and A. Banting. 2005. Evaluation of the economic benefit of systemic treatment with the NSAID meloxicam (Metacam) in endotoxin-induced bovine mastitis. Page 232 in Mastitis in Dairy Production. H. Hogoveen, ed. Wageningen Academic Publishers, Wageningen, the Netherlands.

Friton, G., H. Phillip, and R. Kleemann. 2002. Efficacy of meloxicam (Metacam) in lactating cows with acute mastitis. Page 427 in Proc. XXII World Buiatrics Congr. World Assoc. Buiatrics. German Association of Buiatrics, Hanover, Germany.

Gröhn, Y. T., D. J. Wilson, R. N. González, J. A. Hertl, H. Schulte, G. Bennett, and Y. H. Schukken. 2004. Effect of pathogenspecific clinical mastitis on milk yield in dairy cows. J. Dairy Sci. $87: 3358-3374$ 
Hockett, M. E., R. A. Almeida, N. R. Rohrbach, S. P. Oliver, H. H. Dowlen, and F. N. Schrick. 2005. Effects of induced clinical mastitis during preovulation on endocrine and follicular function. J. Dairy Sci. 88:2422-2431.

Hockett, M. E., J. M. Hopkins, M. J. Lewis, A. M. Saxton, H. H. Dowlen, S. P. Oliver, and F. N. Schrick. 2000. Endocrine profiles of dairy cows following experimentally induced clinical mastitis during early lactation. Anim. Reprod. Sci. 58:241-251.

Königsson, K., H. Gustafsson, and H. Kindahl. 2002. 15-KetodihydroPGF2 $\alpha$, progesterone and uterine involution in primiparous cows with induced retained placenta and post-partal endometritis treated with oxytetracycline and flunixin. Reprod. Domest. Anim. $37: 43-51$

Lees, P., M. F. Landoni, J. Giraudel, and P. L. Toutain. 2004. Pharmacodynamics and pharmacokinetics of nonsteroidal antiinflammatory drugs in species of veterinary interest. J. Vet. Pharmacol. Ther. 27:479-490.

McDougall, S. 1998. Efficacy of two antibiotic treatments in curing clinical and subclinical mastitis in lactating dairy cows. N. Z. Vet. J. $46: 226-232$.

McDougall, S., D. G. Arthur, M. A. Bryan, J. J. Vermunt, and A. M. Weir. 2007. Clinical and bacteriological response to treatment of clinical mastitis with one of three intramammary antibiotics. N. Z. Vet. J. 55:161-170.

McDougall, S., F. M. Rhodes, and G. Verkerk. 2005. Pregnancy loss in New Zealand dairy cattle. N. Z. Vet. J. 53:279-287.

McKeown, K. J., J. R. G. Challis, C. Small, L. Adamson, A. D. Bocking, M. Fraser, D. Rurak, K. W. Riggs, and S. J. Lye. 2000. Altered fetal pituitary-adrenal function in the ovine fetus treated with RU486 and meloxicam, an inhibitor of prostaglandin synthase-II. Biol. Reprod. 63:1899-1904.

Nestor, K. E. J., R. W. Hemken, and R. J. Harmon. 1988. Influence of sodium chloride and potassium bicarbonate on udder edema and selected blood parameters. J. Dairy Sci. 71:366-367.

Paape, M. J., D. D. Bannerman, X. Zhao, and J. W. Lee. 2003. The bovine neutrophil: Structure and function in blood and milk. Vet. Res. 34:597-627.

Persson, K., I. Larsson, and C. H. Sandgren. 1993. Effects of certain inflammatory mediators on bovine neutrophil migration in vivo and in vitro. Vet. Immunol. Immunopathol. 37:99-112.

Peter, A. T., P. W. Clark, D. E. Van Roekel, C. W. Luker, J. D. Gaines, and W. T. K. Bosu. 1990. Temporal changes in metabolites of prostanoids in milk of heifers after intramammary infusion of Escherichia coli organisms. Prostaglandins 39:451-457.
Salat, O., F. Sérieys, B. Poutrel, L. Durel, and L. Goby. 2008. Systemic treatment of subclinical mastitis in lactating cows with penethemate hydriodide. J. Dairy Sci. 91:632-640.

Santos, J. E. P., R. L. A. Cerri, M. A. Ballou, G. E. Higginbotham, and J. H. Kirk. 2004. Effect of timing of first clinical mastitis occurrence on lactational and reproductive performance of Holstein dairy cows. Anim. Reprod. Sci. 80:31-45.

Schmitz, S., M. W. Pfaffl, H. H. D. Meyer, and R. M. Bruckmaier. 2004. Short-term changes of mRNA expression of various inflammatory factors and milk proteins in mammary tissue during LPS-induced mastitis. Domest. Anim. Endocrinol. 26:111-126.

Serieys, F., Y. Raguet, L. Goby, H. Schmidt, and G. Friton. 2005. Comparative efficacy of local and systemic antibiotic treatment in lactating cows with clinical mastitis. J. Dairy Sci. 88:93-99.

Shpigel, N. Y., R. Chen, M. Winkler, A. Saran, G. Ziv, and F. Longo. 1994. Anti-inflammatory ketoprofen in the treatment of field cases of bovine mastitis. Res. Vet. Sci. 56:62-68.

Shpigel, N. Y., M. Winkler, A. Saran, and G. Ziv. 1996. The antiinflammatory drugs phenylbutazone and dipyrone in the treatment of field cases of bovine mastitis. J. Vet. Med., Ser. A. 43:331336

Smith, G. 2003. Supportive therapy of the toxic cow. Vet. Clin. North Am. Food Anim. Pract. 21:595-614.

Sordillo, L. M., K. Shafer-Weaver, and D. DeRosa. 1997. Immunobiology of the mammary-gland. J. Dairy Sci. 80:1851-1865.

St Rose, S. G., J. M. Swinkels, W. D. J. Kremer, C. L. J. J. Kruitwagen, and R. N. Zadoks. 2003. Effect of penethamate hydriodide treatment on bacteriological cure, somatic cell count and milk production of cows and quarters with chronic subclinical Streptococcus uberis or Streptococcus dysgalactiae infection. J. Dairy Res. 70:387-394.

Van Hecken, A., J. I. Schwartz, M. Depre, I. De Lepeleire, A. Dallob, W. Tanaka, K. Wynants, A. Buntinx, J. Arnout, P. H. Wong, D. L. Ebel, B. J. Gertz, and P. J. De Schepper. 2000. Comparative inhibitory activity of rofecoxib, meloxicam, diclofenac, ibuprofen, and naproxen on COX-2 versus COX-1 in healthy volunteers. J. Clin. Pharmacol. 40:1109-1120.

Vangroenweghe, F., L. Duchateau, P. Boutet, P. Lekeux, P. Rainard, M. J. Paape, and C. Burvenich. 2005. Effect of carprofen treatment following experimentally induced Escherichia coli mastitis in primiparous cows. J. Dairy Sci. 88:2361-2376.

Wagner, S. A., and M. D. Apley. 2004. Effects of two anti-inflammatory drugs on physiologic variables and milk production in cows with endotoxin-induced mastitis. Am. J. Vet. Res. 65:64-68. 